\title{
Comparative study of aerosol and cloud detected by CALIPSO and OMI
}

submitted to Atmospheric Environment

\author{
Z. Chen ${ }^{1,2}$, O. Torres ${ }^{3}$, M. P. McCormick ${ }^{1}$, W. Smith ${ }^{1}$, and C. Ahn ${ }^{2}$ \\ 'Department of Atmospheric and Planetary Sciences, Hampton University, VA 23668, USA 'Science \\ ${ }^{2}$ Systems and Applications, Inc., Lanham, Maryland, 20706, USA \\ ${ }^{3}$ NASA Goddard Space Flight Center, Greenbelt, Maryland 20771, USA
}

\section{Popular Summary}

The Ozone Monitoring Instrument (OMI) on the Aura Satellite detects the presence of desert dust and smoke particles (also known as aerosols) in terms of a parameter known as the UV Aerosol Index (UVAI). The Cloud-Aerosol Lidar and Infrared Pathfinder Satellite Observations (CALIPSO) mission measures the vertical distribution of aerosols and clouds. Aerosols and clouds play important roles in the atmosphere and climate system. Accurately detecting their presence, altitude, and properties using satellite radiance measurements is a very important task. This paper presents a comparative analysis of the CALIPSO Version 2 Vertical Feature Mask (VFM) product with the (OMI) UV Aerosol Index (UVAI) and reflectivity datasets for a full year of 2007. The comparison is done at regional and global scales. Based on CALIPSO and OMI observations, the vertical and horizontal extent of clouds and aerosols are determined and the effects of aerosol type selection, load, cloud fraction on aerosol identification are discussed. It was found that the spatial-temporal correlation found between CALIPSO and OMI observations, is strongly dependent on aerosol types and cloud contamination. CALIPSO is more sensitivity to cloud and often misidentifies desert dust aerosols as cloud, while some small scale aerosol layers as well as some pollution aerosols are unidentified by OMI UVAI. Large differences in aerosol distribution patterns between CALIPSO and OMI are observed, especially for the smoke and pollution aerosol dominated areas. In addition, the results found a significant correlation between CALIPSO lidar $1064 \mathrm{~nm}$ backscatter and the OMI UVAI over the study regions. 